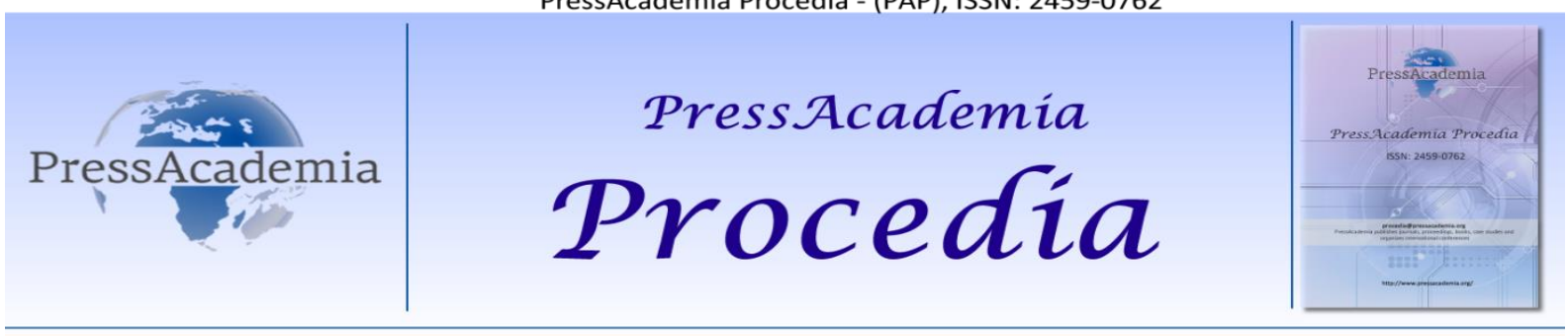

Global Business Research Congress (GBRC), May 24-25, 2017, Istanbul, Turkey

\title{
THE EFFECTS OF THE INFORMATION ON JOB ANALYSIS OBTAINED FROM THE HUMAN RESOURCES INFORMATION SYSTEM ON INFORMATION HEALTH
}

\section{DOI: 10.17261/Pressacademia.2017.652 \\ PAP- GBRC-V.3-2017(78)-p.746-751}

Nezih Metin Özmutaf ${ }^{1}$, Elif Aktekin ${ }^{2}$, Bulent Ergani ${ }^{3}$

${ }^{1}$ izmir Kâtip Celebi University, Cigli/izmir, Türkiye. nezih.metin.ozmutaf@ikc.edu.tr

${ }^{2}$ Ege University Atatürk Health Care Vocational School, Bornova/izmir, Türkiye. elif aktekin@ hotmail.com

${ }^{3}$ İzmir Kâtip Celebi University, Cigli/izmir, Türkiye. bulenter 3543@hotmail.com

\section{To cite this document}

Ozmutaf, N , E. Aktekin, B. Ergani (2017). The effects of the information on job analysis obtained from the hr information system on information health. PressAcademia Procedia (PAP), V.3, p.746-751.

Permemant link to this document: $h$ ttp://doi.org/10.17261/Pressacademia.2017.652

Copyright: Published by PressAcademia and limited licenced re-use rights only.

\section{ABSTRACT}

The main goal of the research is to determine the perception of managers working in food production companies in Eagean Region on the information on business analysis obtained from the human resources (HR) information system on information health. The survey form of the study was applied face to face interview or through e-mail to 63 managers working at food production companies in Aegean Region between March 2016-June 2016. According to research results, business analysis factors of data / information derived from HR information systems "leadership, motivation, communication, organizational relations, cooperation, audit of the work, mission, responsibility, jurisdiction, performance standards, mental and physical effort, way of doing work, technology equipment tools materials used in work, work information, to be open to learning, job related skills, relations with other works, education, working conditions and capabilities" effect information health positively. Efficient use of information obtained from HR information systems can provide strategic advantages to businesses.

Keywords: HR information systems, business analysis, information health, yönetim bilgi sistemleri JEL Codes: L10, L25, M10

\section{INSAN KAYNAKLARI BILGI SISTEMINDEN ELDE EDILEN IŞ ANALIZi KAPSAMINDAKI BíLGILERIN BiLGi SAĞLIĞINA ETKISI}

\section{ÖZET}

Araştırmanın temel amacı, Ege Bölgesi'nde gıda üretimi yapan firmaların insan kaynakları (IK) bilgi sistemlerinden elde edilen iş analizine yönelik bilgiler kapsamında bilgi sağlığına yönelik yönetici algılarının belirlenmesidir. Araştırmaya yönelik olarak hazırlanan anket formu Ege Bölgesi'nde gıda üretimi yapan 63 firmada yüz yüze anket ve e-mail yöntemi ile Mart 2016 - Haziran 2016 tarihleri arasında 63 yöneticisiye uygulanmıştır. Araştırma sonucunda iK bilgi sisteminden elde edilen data / bilgilerin iş analizi unsurları (liderlik, motivasyon, iletişim, örgütsel ilişkiler, iş birliği, işin denetimi, görev, sorumluluk, yetki alanı, performans standartları, zihinsel ve fiziksel çaba, işin yapılış biçimi, kullanılan teknoloji, araç, gereç, techizati malzeme, iş bilgisi, öğrenmeye açıklık, iş becerisi, iş ilişkileri, eğitim, çalışma koşulları ve yetenek) kapsamında bilgi sağlı̆̆ını ileri düzeyde pozitif yönde etkilemektedir. í bilgi sistemlerinden elde edilen bilgilerin etkin kullanımı işletmelere stratejik avantajlar sağlayabilecektir.

Anahtar Kelimeler: İK bilgi sistemi, iş analizi, bilgi sağlığı, management information systems JEL Kodları: L10, L25, M10 


\section{GíRiş}

İnsan Kaynakları (IK) uygulamaları iş analizi ile başlamaktadır. İ̧ Analizi sonucunda elde edilen verilerin, işletme faaliyetlerinin temel yapı taşlarını oluşturduğu söylenebilir. Sağlıklı bilgi edinimi ancak çağdaş yaklaşımlarla mümkün olabilecektir. Bu amaçla bilgi sistemlerinin geliştirilmesi ve etkin kullanımı işletmelere rekabet avantajı sağlayabilecek unsurlardandır. Sağlıklı bilgi, gelişen örgütlerin pazardaki rekabet avantajı için stratejik bir gerçekliktir. Bilgi stratejisinin yönetimi, bilgiyi toplama, oluşturma, geliştirme, paylaşma, kullanma ve stratejik bir biçimde değerlendirme anlamına gelir (Barutçugil, 2002: 101). Kurumun genel bilgi sisteminin bir parçası olan íK bilgi sistemi, insan kaynakları işlevleri açısından sağlıklı bilgilerin yönetimini sağlar. Bu bağlamda, araştırmanın amacı, Ege Bölgesinde gıda üretimi yapan firmalarda çalışan yöneticilerin, ik bilgi sisteminden iş analizi kapsamında elde edinilen bilgilerin bilgi sağlığı konusundaki algılarını belirlemektir. Araştırmanın anket formu, Mart 2016 - Haziran 2016 tarihleri arasında Ege Bölgesinde üretim ve ihracat yapan firmalarda çalışan 63 yöneticiye uygulanmıştır.

\section{LITERATÜR INCELEMESI}

\section{1. İnsan Kaynakları Bilgi Sistemleri}

ik Bilgi sistemleri, "Bir örgütün insan kaynakları fonksiyonunun etkin olarak işlemesine yardım etmek için örgütün insan kaynakları ile ilgili bireysel ve tüm insan kaynakları faaliyetleri ile ilgili örgütsel verilerin toplanması, saklanması, güncelleştirilmesi, stratejik ve yönetsel kararların verilmesine yardımcı olacak biçimde bilgi haline dönüştürülmesini sağlayan sistem" olarak ortaya konabilir (Öge, 2005:112). Sistemin amacı, uygun zamanda, tam ve doğru enformasyonu sağlamak ve insan kaynağına dönük kararlar verecek olan ilgililere faydalı enformasyonu sağlamaktır. Günümüzde etkin insan kaynakları yönetiminin işletmelerde deneyim gerektiren bir uzmanlık alanı olduğu bilinci ortaya çıkmıştır. İnsan kaynakları departmanı firmanın gelişme ve büyüme stratejisine altyapı hazırlamaktadır. Bu sayede işgören için şartların iyileştirilmesi ona işin vazgeçilmez kaynaklarından biri olduğunu göstermektedir. İnsan artık şirketler için vazgeçilmez bir sermayedir. Insan kaynakları, sorumluluk alanlarının dışında kurum kültürü yaratma, kurumsal iletişim ve çalışanların yetkinliklerinin geliştirilmesi yönüne büyük önem vermektedir (Gökalp, 2005:1).

İnsan kaynaklarına yatırım yapan şirketlerin bu işler için ayırdığı bütçeler oldukça yüksektir. Çalışanlar için planlanan eğitim, kaynak kullanım, oryantasyon v.s. gibi konularda doğacak zaman ve diğer maliyetleri azaltmak, ancak teknolojiyi kaynak kullanımı ile birleştirerek mümkün olmaktadır. Sürekli iyileşme sürecinde işletmenin çevresi ile iletişimi sağlayan bilgi sistemlerinin, yöneticinin etkin kararlar alabilmesi ve bunları uygulayabilmesi için yeterli bilgiyi üretmesi ve sunması gerekir. Bu bağlamda yöneticilere istenilen yer ve zamanda bilginin hazır edilmesi bilgi sistemlerinin temel fonksiyonudur. Dolayısıyla bilgi ve bilgiyi farklı kademeler için işleyen ve değişik şekillerde sunan bilgi sistemleri, geleceğe yönelik planlar oluşturma, bu planları uygulama ve kontrol etme imkanı vermektedir (URL 1). Genel olarak, bugünün yöneticileri birincil güç kaynağının bilgi olduğunu vurgular ve bu, kuruluşta neler olduğunu anlamaya yardımcı olur. Bu bağlamda, bilgiler bilgi sistemlerinde saklanabilir (Stoner, Freeman, Gilbert, 1995: 545). Bir organizasyonda, bilgi sistemleri uygulamasında görev düzenlemeleri, yapılar ve çalışanlarla ilgili sonuçlar elde edilmelidir. Dolayısıyla, İK bilgi sistemi bilgi / veri akışını kolaylıkla gerçekleştirebilir (Laudon ve Laudon, 2012: 93).

\section{2. İ̧̧ Analizi ve Bilgi Sağlığı}

Temel olarak, üstten alta doğru örgütlerdeki İk bilgi sistemleri stratejik, taktiksel ve operasyonel seviyeden oluşur. Stratejik grupta ík sistemleri, iş̧̧i müzakere sistemi, iK, muhasebe sistemleri yer alırken taktik seviyede iş analizi ve tasarımı, iş̧̧i toplama sistemleri, eğitim ve gelişim sistemleri, ödül sistemleri bulunmaktadır. Operasyonel seviyede ise resmi rapor, bordro, personel dosyaları, pozisyon ve beceri stok, devamsızlık ve izin durumları yer almaktadır. (Sabuncuoğlu, 2009: 345). ík yönetiminde iş analizi, iş ile ilgili görevler, sorumluluklar ve çalışma koşulları, teknoloji, ekipman, malzemeler, zihinsel süreç vb. sağlar (Jones and George, 2006: 421). Liderlik, motivasyon, iletişim, örgütsel ilişkiler, işbirliği ve iş kontrol konuları yöneticilerin iş analizi kapsamına eklenebilir (Ertürk, 2011: 31). Taktiksel seviyede yer alan iş analizi kapsamında toplanan verilerin, işlenerek bilgiye dönüştürülmesi ve ihtiyaç duyulan durumların yanı sıra gelecekle ilgili alınacak kararlarda değerlendirilmesi bilgi yönetimi sürecini göstermektedir.

İ̧ analizi bilgileri ík bilgi sisteminde güncellenebilir ve işlevsel olduğunda sağlıklı olarak ifade edilir. Sağlıklı bilgiler şirkete rekabet avantajı, verimlilik, kalite, maliyet minimizasyonu, güvenilirlik, verimlilik, karlılık ve yüksek performans gibi birçok fayda sağlayacaktır (Sabuncuoğlu, 2009: 341). 


\section{VERI VE YÖNTEM}

Araştırma için hazırlanan anket formu iki temel bölümden oluşmaktadır. Birinci bölümde, araştırmanın bağımsız değişkenleri olan yaş, eğitim durumu, görev alanı, mesleki çalışma süresi, işletme yaşı, bilgi sistemini kullanım süresi, bilgi sistemini kullanım süresi, işletmedeki çalışan sayısı, işletmedeki bilgi sistemindeki çalışan sayısı ve bilgi sisteminin işletmeye yıllık maliyeti yer almaktadır. Anketin ikinci bölümünde İK bilgi sisteminden elde edilen data / bilgilerin iş analizi kapsamında bilgi sağlığına etkilerine yönelik 21 önerme yer almıştır. Önermelere istatistiksel değerlendirmeler için 5'li Likert ölçeği kapsamında kesinlikle katılmıyorum için 1, katılmıyorum için 2, orta düzeyde katılıyorum için 3, katılıyorum için 4, kesinlikle sisteminin katılıyorum için 5 ağırık değeri verilmiştir. 21 önerme faktör analizi sonucu 7 faktör altında toplanmıştır. Araştırmaya yönelik olarak hazırlanan anket formu Ege ìhracatçılar Birliğine kayıtlı, gıda sektöründe faaliyet gösteren, üretim, ihracat ve ithalat yapan 63 firmada yüz yüze anket ve e-mail yöntemi ile Mart 2016 - Haziran 2016 tarihleri arasında 63 yöneticiye uygulanmıştır. Araştırmada istatistiksel analizler kapsamında SPSS yazılımı kullanılmıştır. Araştırma kapsamında faktör analizi ve evren ortalamasına dayalı t testi yapıımıştır.

\subsection{Araştırmanın modeli}

Araştımanın teorik modeli, Ege Bölgesi'nde gıda üretimi yapan firmalardaki yöneticilerin İ bilgi sisteminden elde edilen bilgilerin iş analizi kapsamında bilgi sağlığına etkisi olduğu varsayımı üzerine kurulmuştur (Bkz. Şekil 1).

\section{Şekil 1: Araştırmanın Teorik Modeli}

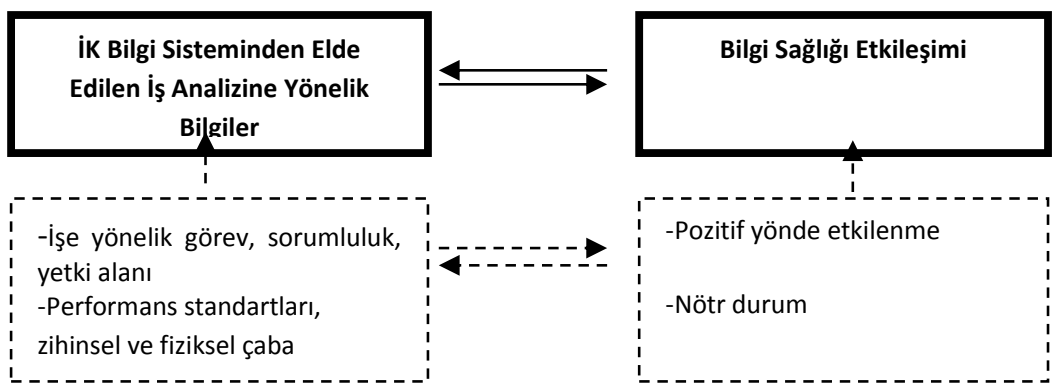

\subsection{Araştırmanın Temel Hipotezi}

$\mathrm{H}_{0}$ : Gıda üretimi yapan firmalar da iK bilgi sisteminden elde edilen ... kapsamında bilgi sağlığı pozitif yönde etkilenmemektedir.

$\mathrm{H}_{1}$ : Gıda üretimi yapan firmalar da İ bilgi sisteminden elde edilen ... kapsamında bilgi sağlığı pozitif yönde etkilenmektedir.

\section{BULGULAR VE TARTIŞMA}

\subsection{Bağımsız Değişkenlere Yönelik Bulgular}

Ankete katılan yöneticilerin ( $n=63$ ) yaş (min-max=28-68) ortalaması ve standart sapması $45,1 \pm 9,44^{\prime}$ tür. Ankete katılan yöneticilerin çoğunluğu lise ve ön lisans / lisans seviyesinde eğitime sahiptir. Yöneticilerin büyük çoğunluğu 10 yıl ve üstü yıl mesleki deneyime sahiptir (Tablo 1).

Tablo 1: Yöneticilerin Eğitim Durumu ve Mesleki Çalışma Süreleri

\begin{tabular}{|l|c|c|l|c|c|}
\hline \multicolumn{1}{|c|}{ Eğitim } & $\mathbf{n}$ & $\mathbf{\%}$ & $\begin{array}{l}\text { Mesleki Çalışma } \\
\text { Süresi (yıl) }\end{array}$ & $\mathbf{n}$ & $\mathbf{\%}$ \\
\hline Lise & 34 & 54,0 & $<10$ & 6 & 9,5 \\
\hline Önlisans/Lisans & 23 & 36,5 & $>=10$ & 57 & 90,5 \\
\hline Lisansüstü & 6 & 9,5 & Toplam & 63 & 100,0 \\
\hline Toplam & 63 & 100,0 & & & \\
\hline
\end{tabular}


Yöneticilerin yer aldığı işletmelerin çoğunluğu 10 yıldan fazla süredir faaliyet göstermektedir. İşletmelerin büyük çoğunluğu küçük ölçekli ve çok azı orta ölçekli işletmedir. İşletmedeki İK bilgi sisteminde çalışan personelin büyük çoğunluğu 1 ve 2 kişidir. İK bilgi sistemini kullanım süresi çoğunluğunda 10 yıl ve üstüdür. Yine işletmelerin büyük çoğunluğu İ bilgi sistemini 1 ya da 2 yıl da bir güncellemektedir. İ bilgi sisteminin işletmelere maliyeti çoğu işletme için 5000 TL'nin altındadır (Tablo 2).

Tablo 2: İşletme ve í Bilgi Sistemi

\begin{tabular}{|c|c|c|c|c|c|}
\hline İşletme Yaşı & $\mathbf{n}$ & $\%$ & Bilgi Sistemini Kullanım Süresi (yıl) & $\mathbf{n}$ & $\%$ \\
\hline$<10$ & 19 & 30,2 & $<10$ & 21 & 33,3 \\
\hline$>=10$ & 44 & 69,8 & $>=10$ & 42 & 66,7 \\
\hline Toplam & 63 & 100,0 & Toplam & 63 & 100,0 \\
\hline İşletme Çalışan Sayısı & $\mathbf{n}$ & $\%$ & Bilgi Sistemini Güncelleme Süresi (yıl) & $\mathbf{n}$ & $\%$ \\
\hline$<50$ & 55 & 87,3 & 1,00 & 39 & 61,9 \\
\hline $50-250$ & 8 & 12,7 & 2,00 & 23 & 36,5 \\
\hline Toplam & 63 & 100,0 & 3,00 & 1 & 1,6 \\
\hline Bilgi Sisteminde Çalışan Sayısı & $\mathbf{n}$ & $\%$ & Toplam & 63 & 100,0 \\
\hline 1,00 & 39 & 61,9 & Bilgi Sisteminin İşletmeye Maliyeti & $\mathbf{n}$ & $\%$ \\
\hline 2,00 & 20 & 31,7 & $<5000$ & 46 & 73,0 \\
\hline 3,00 & 4 & 6,3 & $>=5000$ & 17 & 27,0 \\
\hline Toplam & 63 & 100,0 & Toplam & 63 & 100,0 \\
\hline
\end{tabular}

\section{2. Ölçüm Aracının Güvenirliği}

Anketin ikinci bölümünde yer alan 21 önermeye temel bileşenler analizi kapsamında faktör analizi uygulanmıştır. KaiserMeyer-Olkin değeri 0,682'dir. Bartlett Küresellik Testi sonucunda sıfır hipotezi ( $\mathrm{H}_{0}$ : korelasyon matrisi birim matristir) reddedilmiştir $\left(\chi_{210}^{2}=589,695, p=0.000\right)$. Anti imaj korelasyon matrisinin köşegen değerleri 0,761- 524 arasında değer almıştır. Bu bulgular kapsamında 21 soruluk önermeden oluşan yapının faktör analizine uygunluğuna karar verilmiştir. Faktör analizi sonucu oluşan 7 faktör çerçevesinde toplam varyans \% 71,946 sviyesinde açıklamaktadır. Toplam varyansın; birinci faktör \%21,716'sını, ikinci faktör \%10,256'sını, üçüncü faktör \%9,743'ünü, dördüncü faktör \%8,371'ini, beşinci faktör \%7,736'sını, altıncı faktör \%7,271'ini ve yedinci faktör \%6,852'sini açıklamaktadır. Beş faktörlük yapının Cronbach Alfa değeri $0.814^{\prime}$ tür. Bu sonuca göre ankette yer alan önermelerin işaret ettiği faktörler konuyu yüksek düzeyde güvenilir olarak açıklamaktadır (Tablo 3).

7 faktör altında toplanan 21 önermenin tamamı için $\mathrm{H}_{1}$ hipotezi kabul edilmiștir. Diğer bir deyişle yönetici algılarına göre; iK bilgi sisteminden elde edilen data ya da bilgiler önermelerin her biri kapsamında işletmedeki bilgi sağlığını ileri düzeyde pozitif yönde etkilemektedir (Tablo 3). 
Tablo 3: Faktör Analizi ve Tek Örnek t Testi

\begin{tabular}{|c|c|c|c|c|c|c|c|c|c|c|}
\hline \multirow{2}{*}{$\begin{array}{l}\text { Bilgi sisteminden elde edilen data } \\
\text { ya da bilgi.......................... } \\
\text { kapsamında bilgi sağlığını pozitif } \\
\text { yönde etkiler }\end{array}$} & \multicolumn{7}{|c|}{ Faktör } & \multicolumn{3}{|c|}{$\begin{array}{l}\text { Tek Örnek t testi } \\
\text { (Test Değeri } 3 \leq \mu \text { ) }\end{array}$} \\
\hline & 1 & 2 & 3 & 4 & 5 & 6 & 7 & $\bar{x} \pm s$ & $\mathrm{t}$ & $\mathrm{p}$ \\
\hline Liderlik & ,915 & ,056 & ,069 &,- 055 &,- 017 &,- 014 & ,014 & $4,5 \pm, 53$ & 23,203 & 0,000 \\
\hline Motivasyon & ,876 & ,100 &,- 018 & ,146 & ,207 &,- 040 & ,126 & $4,5 \pm, 53$ & 22,372 & 0,000 \\
\hline İletişim & ,846 & ,057 & ,186 & ,158 &,- 035 &,- 147 & ,049 & $4,5 \pm, 53$ & 23,203 & 0,000 \\
\hline Örgütsel İlişkiler & ,832 & ,133 & ,029 &,- 076 &,- 069 & 199 &,- 110 & $4,5 \pm, 53$ & 23,203 & 0,000 \\
\hline İşbirliği & ,710 &,- 026 & ,422 &,- 065 & , 168 & , 156 & ,085 & $4,4 \pm, 53$ & 21,386 & 0,000 \\
\hline İşin denetimi & ,685 & ,215 & ,256 & ,226 & ,097 &, 064 & , 155 & $4,5 \pm, 50$ & 23,750 & 0,000 \\
\hline İş'e yönelik görev & , 183 & ,866 &,- 042 &, 029 & ,113 &,- 161 &,- 142 & $4,4 \pm, 66$ & 17,048 & 0,000 \\
\hline İş'e yönelik sorumluluk & ,201 & ,805 &,- 116 &,- 178 & ,200 & ,032 & ,052 & $4,4 \pm, 66$ & 17,197 & 0,000 \\
\hline İş’e yönelik yetki alanı &,- 068 & ,692 & ,079 & ,305 &,- 292 & ,218 & 085 & $4,2 \pm, 65$ & 15,505 & 0,000 \\
\hline Performans standartları &, 024 &,- 051 & ,794 &,- 117 &,- 147 & ,070 &,- 196 & $4,3 \pm, 71$ & 14,636 & 0,000 \\
\hline Zihinsel çaba & ,296 &,- 044 & ,758 & ,153 & ,061 &,- 043 & ,116 & $4,4 \pm, 68$ & 16,319 & 0,000 \\
\hline Fiziksel çaba & ,295 &,- 001 & ,625 & ,167 & ,320 &,- 229 & ,041 & $4,4 \pm, 56$ & 20,588 & 0,000 \\
\hline İşin yapılış biçimi &,- 004 &,- 078 &, 000 & ,852 & ,053 &,- 072 & ,016 & $4,5 \pm, 50$ & 23,750 & 0,000 \\
\hline $\begin{array}{l}\text { İş'te kullanılan teknoloji, araç, } \\
\text { gereç, teçhizat, malzeme vb. }\end{array}$ & ,213 & 298 & 153 & ,664 & ,163 & ,292 &,- 066 & $4,5 \pm, 50$ & 23,750 & 0,000 \\
\hline Çalışanın iş bilgisi & 059 & 111 & ,018 & ,096 &, 800 & ,153 &,- 020 & $4,5 \pm, 50$ & 24,324 & 0,000 \\
\hline Çalışanın öğrenmeye açık olması & ,470 &,- 165 &, 023 & ,415 & ,484 &,- 005 &, 024 & $4,4 \pm, 50$ & 23,273 & 0,000 \\
\hline Çalışanın işle ilgili becerisi &, 013 &,- 073 &,- 120 &,- 011 & 140 & ,810 &,- 067 & $4,5 \pm, 50$ & 23,750 & 0,000 \\
\hline Diğer işler ile ilişkiler &,- 012 & ,197 & ,304 & ,016 & ,434 &, 528 & ,138 & $4,3 \pm, 68$ & 15,036 & 0,000 \\
\hline Çalışanın eğitimi & ,201 & ,047 &,- 059 & ,313 &,- 267 & ,478 & ,325 & $4,4 \pm, 50$ & 22,889 & 0,000 \\
\hline İşe yönelik çalışma koşulları & ,019 &,- 089 &, 047 & ,063 &,- 191 & ,126 & ,778 & $4,3 \pm, 48$ & 22,391 & 0,000 \\
\hline Çalışanın iş ile ilgili yetenekleri & ,103 & ,056 &,- 083 &,- 083 & ,230 &,- 093 & ,744 & $4,5 \pm, 50$ & 24,650 & 0,000 \\
\hline
\end{tabular}

\section{SONUÇ}

IK faaliyetleri iş analizi sonucu elde edilen bilgilerle başlamakta ve devam etmektedir. Bu çerçevede iş analizi için elde edilen bilgilerin sağ ıklı olması tüm ík süreçlerini de sağlıklı konuma taşıyabilecektir. Sağlıklı bilgi ediniminin çağdaş yapılanması ise bilgi sistemlerinden elde edilen data / bilgiler şeklinde olduğu da günümüzde ifade edilebilecektir. Bu çalışma kapsamında bilgi sisteminden elde edilen bilgilerin geniş bir bakış açısı ile iş analizi kapsamında araştırma boyutları olarak ifade edilebilecek; "liderlik, motivasyon, iletişim, örgütsel ilişkiler, iş birliği, işin denetimi, görev, sorumluluk, yetki alanı, performans standartları, zihinsel ve fiziksel çaba, işin yapılış biçimi, kullanılan teknoloji, araç, gereç, techizati malzeme, iş bilgisi, öğrenmeye açıkık, iş becerisi, iş ilişkileri, eğitim, çalışma koşulları ve yetenek" çerçevesinde bilgi sağlığını ileri düzeyde pozitif yönde etkilediği yönetici görüşleri kapsamında belirlenmiştir.

Çalışma aşağıdaki katkıları sağlamıştır:

i. $\quad$ İş analizi konusu ve boyutları hemen her İKY ile ilgili kaynakta yer alabilmektedir. Ancak bu çalışma ile iK bilgi sistemi, iş analizi kapsamında bilgi sağlığı ile ilişkiselleştirilerek beraberce ele alınmıştır. 
ii. Çalışma uygulama ve teorik boyutları birleştirmiştir. Bu bağlamda Ege Bölgesi'nde sektörel olarak önemli bir yer tutan gıda üretimi yapan firmaların hedef kitle olarak kabul edilmesi de konuya derinlik kazandırmıştır.

\section{KAYNAKLAR}

Barutçugil, ì. (2002). Bilgi Yönetimi. İstanbul: Kariyer Yayıncılık.

Ertürk, M. (2011). İnsan Kaynakları Yönetimi. İstanbul: Beta Yayım Dağıtım.

Gökalp Z., İnsan Kaynakları Yönetimi ve Teknoloji, Erişim Tarihi:01.05.2017 http://www.bilgiyonetimi.org/cm/pages/mkl_gos.php?nt=136 Jones, G.R., and George, J.M. (2006). Contemporary management. New York: McGraw- Hill Irwin Laudon J.P. ve Laudon K.C ( 2012). Management Information Systems.New Jersey:Prentice Hall,

Öge, S. (2005), “Elektronik İnsan Kaynakları Yönetiminde İnsan Kaynakları Enformasyon Sisteminin Önemi ve Temel Kullanım Alanları”, Selçuk Üniversitesi

Sabuncuoğlu, Z. (2009). İnsan Kaynakları Yönetimi. Bursa: Furkan Ofset.

Stoner J.A.F, Freeman R.E, Gilbert D.A (1995). Management. New Jersey:Prentice Hall. Prentice-Hall International, ISBN 0131494449, 9780131494442

URL 1: http://kaankarabulut/insan-kaynaklari-bilgi-sistemlerinin-gelecegi/7938114 Erişim:10.03.2017 